\title{
Abrasion Behaviour of Wool-Viscose Hand Tufted Carpets Using Response Surface Methodology
}

\author{
Shravan Kumar Gupta ${ }^{1}$, Anupam Agarwal ${ }^{1}$, Anupam Kumar ${ }^{2}$ \\ ${ }^{1}$ Indian Institute of Carpet Technology Chauri Road, Bhadohi, Uttar Pradesh - 221401 \\ ${ }^{2}$ Gyani Jail Singh Campus College of Engineering and Technology, Bathinda, Punjab, India - 151001
}

\begin{abstract}
The effect of viscose blend in pile yarn, pile height and pile density on abrasion resistance of hand tufted carpets has been studied. The interaction between the process variables has been analyzed by using response surface methodology based on the Box-Behnken design of experiment. Overall, higher percentage (\%) of viscose in the blend, lower pile height and lower pile density yield the minimum abrasion loss for the hand tufted carpets.
\end{abstract}

Keywords: Abrasion resistance; Box-Behnken design; Hand tufted carpet; Response surface methodology

\section{Introduction}

Indian carpet industry is the number one in the international handmade carpet market both in term of value and volume. India exports $90 \%$ of its total handmade carpet production. Indian handmade carpet industry is highly labour intensive and provide employment to about 20 lakh workers. Most of the weaver employed are from the weaker section of the society and this trade provide extra and alternate ocupation to them ${ }^{[1]}$. A carpet is a textile floor covering typically consisting of an upper layer of pile attached to a backing ${ }^{[2]}$. Handmade carpets are classified into three different types like knotted (Persian, Tibetan, Turkish etc.), tufted (hand tufting and needle tufting) and flat woven (broad loom carpets, saggy, durry etc. $)^{[3-5]}$. Wool, silk, polypropylene and nylon fibres are used as pile fibres; whereas cotton, jute, polyester and polypropylene fibres are used as backing in manufacturing of handmade carpets. Wool as pile yarn is generally used in handmade carpets due to its outstanding properties such as hand, durability, stain resistance, dyeability, flame resistance, insulation, static generation and biodegrability. The woollen pile yarns usually consist of twisted tufts which are typically heat-treated to maintain their structure ${ }^{[6]}$.

Carpet durability is defined as the wear life of a carpet in specified situations. Durability property is important for carpet manufacturers to meet the customer requirements on the basis of their end-uses. Gupta et al. ${ }^{[7]}$ reviewed various methods for measuring carpet durability like abrasion resistance, compression and recovery characteristics, tuft withdrawal force, thickness loss under dynamic loading, thickness loss and recovery after prolonged heavy static loading, surface pile mass density factor, appearance retention etc. Among these, abrasion resistance is one of the most important properties of carpet durability. WIRA carpet abrasion machine is extensively used to judge the abrasion behaviour of carpets. Abrasion behaviour of carpets is collectively influenced by fibre, yarn and carpet constructional parameters. Gupta et al..$^{[8]}$ studied the influence of fibre diameter and medullation on abrasion behavior of hand-knotted carpets and found that the abrasion loss increases with the increase in fibre diameter and medullated fibre content in carpet. Shakyawar et al. ${ }^{[9]}$ also reported that the abrasion loss of carpets depends on fibre diameter and number of medullated fibres present in the yarn. Arora et al. ${ }^{[10]}$ studied the influence of tuft constitution (the number of threads assembled together to form a tuft whether single or plied) on the performance parameters of hand-woven carpets. They found lower abrasion loss in carpets having more regular pile surface (when using single ply yarn) than in carpets having reduced regularity in pile surface (when using plied yarn).

The influence of carpet constructional parameters on the abrasion behaviour has been reported by some researchers ${ }^{[9,11-14]}$. It has been found that pile density and pile height play an important role in determining carpet

Copyright (C) 2018 Shravan Kumar Gupta et al.

doi: 10.24294/jpse.v1i3.866

EnPress Publisher LLC.This work is licensed under the Creative Commons Attribution-NonCommercial 4.0 International License (CC BY-NC 4.0). http://creativecommons.org/licenses/ by/4.0/ 
abrasion behaviour.

In these days, viscose fibre is gaining its popularity for using in hand made carpet as a pile yarn. But, there is hardly any reference about the basic characterstics of wool-viscose handmade carpets in terms of its abrasion behaviors. In this research; the influence of three variables (blend percentage $(\%)$ of viscose and wool, pile height and pile density) and their interaction have been studied by developing a model using Box-Behnken response surface methodology. The abrasion behaviour of hand tufted carpets has been investigated to explore its possibility as a new generation product in various product mix.

\section{Materials and methods}

\subsection{Box Behnken methodology}

In statistics, Box-Behnken design (BBD) is most common experimental design for responce surface methodology (RSM), devised by George E. P. Box and Donald Behnken in $1960^{[15]}$. Each factor or independent variable is placed at one of the three equally spaced value usually coded as $-1,0,+1$. The design should be sufficient to fit a quardratic model, that is one containing linear, square and interaction terms. In three factors and three levels BBD, 15 experiments are conducted whereas in a full factorial design 27 experiments will be needed.

\subsection{Sample preparation}

Three types of pile yarns were used for the manufacturing of hand tufted carpet samples by using $40 \%, 60 \%$ and $80 \%$ of viscose fibres blend with wool fibres. The specifications of wool and viscose fibres are depicted in Table 1. Pile yarns of 2.0 metric counts (Nm) with 3.5 twists per inch (tpi) were produced by woollen spinning system.

\begin{tabular}{|l|l|}
\hline \multicolumn{2}{|l|}{ Specification of wool fibre } \\
\hline Mean fibre diameter & 32 micron \\
\hline Fibre diameter (CV \%) & $21 \%$ \\
\hline Mean fibre length & $70 \mathrm{~mm}$ \\
\hline Fibre length (CV \%) & $22.5 \%$ \\
\hline Specification of viscose fibre \\
\hline Mean fibre diameter & $12 \mathrm{micron}$ \\
\hline Fibre diameter (CV \%) & $9 \%$ \\
\hline Mean fibre length & $44 \mathrm{~mm}$ \\
\hline Fibre length (CV \%) & $8 \%$ \\
\hline
\end{tabular}

Table 1. Specifications of wool and viscose fibre
A three factor three level Box-Behnken experimental design was used for this research. The coded and actual levels of variables are given in Table 2.

\begin{tabular}{|c|c|c|c|c|}
\hline \multirow{2}{*}{$\begin{array}{l}\text { Variabl } \\
\text { e code }\end{array}$} & \multirow{2}{*}{$\begin{array}{l}\text { Variables } \\
\text { (unit) }\end{array}$} & \multicolumn{3}{|l|}{ Levels } \\
\hline & & -1 & 0 & +1 \\
\hline $\mathrm{x}_{1}$ & $\begin{array}{l}\text { Viscose bl } \\
\text { end }(\%)\end{array}$ & $\begin{array}{l}40 \% \\
\text { viscose } \\
60 \% \\
\text { wool }\end{array}$ & $\begin{array}{l}60 \quad \% \\
\text { viscose } \\
40 \quad \% \\
\text { wool }\end{array}$ & $\begin{array}{l}80 \% \\
\text { viscose } \\
20 \% \\
\text { wool }\end{array}$ \\
\hline $\mathrm{x}_{2}$ & $\begin{array}{l}\text { Pile } \\
\text { height } \\
(\mathrm{mm})\end{array}$ & 9 & 12 & 15 \\
\hline $\mathrm{x}_{3}$ & $\begin{array}{l}\text { Pile } \\
\text { density } \\
\text { (tufts } \\
\text { /square } \\
\text { inch ) }\end{array}$ & 16 & 20 & 24 \\
\hline
\end{tabular}

Table 2. Coded and actual levels of variables.

Carpet samples were manufactured by hand tufting process. It is process to manufacture the carpet by the insertion of pile yarn into primary backing fabric with the help of tufting gun (Figure 1).

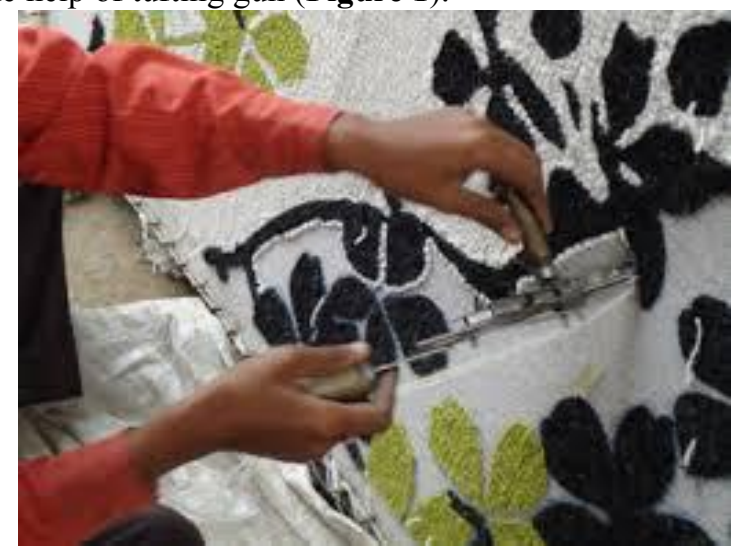

Figure 1; Tufting process.

Specification of primary backing fabric used in this research is depicted in Table 3. 


\begin{tabular}{|l|l|l|}
\hline S. No. & Parameter & Value \\
\hline 1. & Warp count & $2 / 10$ double \\
\hline 2. & Weft count & $2 / 10$ double \\
\hline $\mathbf{3 .}$ & Reed count & 14 to 16 Nos \\
\hline $\mathbf{4 .}$ & Picks/Inch & 14 minimum \\
\hline $\mathbf{5 .}$ & Length & as desired \\
\hline $\mathbf{6 .}$ & Width & $12^{1}{ }^{\prime}{ }^{\prime}$ to $20^{\prime}$ as desired \\
\hline $\mathbf{7 .}$ & $\begin{array}{l}\text { Square meter } \\
\text { weight }\end{array}$ & 300 gm. \\
\hline $\mathbf{8 .}$ & $\begin{array}{l}\text { Weaving } \\
\text { defects }\end{array}$ & Nil \\
\hline
\end{tabular}

Table 3. Specification of primary backing fabric

\subsection{Sample testing}

Pile height: The pile height of carpets was measured as per IS: 7877 (Part IV) - 1976 (Reaffirmed 1997) using flat metal gauges of known height.

Abrasion resistance: The abrasion resistance of carpets was tested by rubbing the carpet samples against a standard abraded fabric for 5000 number of rotations. The WIRA abrasion tester (Figure 2) was used for conducting this test, based on the Schiefer principle of offset heads rotating in the same direction at the same speed. The rate of weight loss per 1000 number of rotations was calculated as per IWS/TM - 283: 2000 standards. For each sample 5 readings were taken and then the average was calculated. Figure 3 depicts samples no 11 (before and after abrasion).

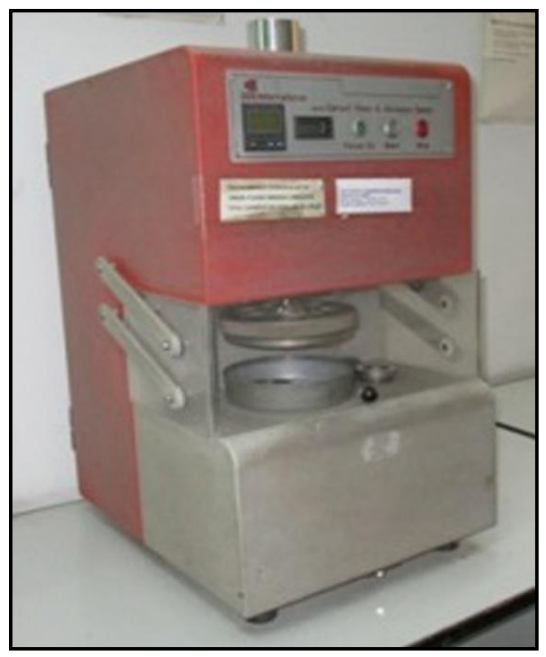

Figure 2; WIRA abrasion tester.

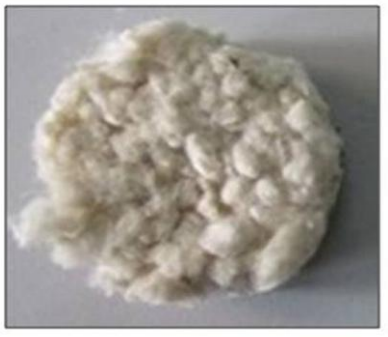

(a) Before abrasion

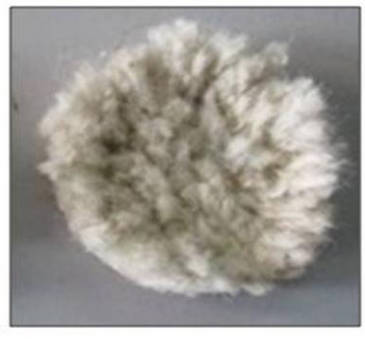

(b) After abrasion
Figure 3; Images of sample number 11.

\section{Results and discussion}

\subsection{Response surface model for abrasion loss}

Table 4 presents the details of experimental and predicted results for the abrasion loss of hand tufted carpets.

\begin{tabular}{|c|c|c|c|c|c|c|}
\hline $\begin{array}{l}\coprod_{2} \\
\text { Za }\end{array}$ & 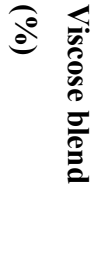 & 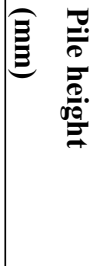 & 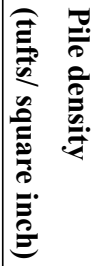 & 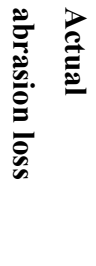 & 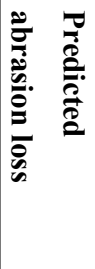 & $\frac{\sqrt{3}}{3}$ \\
\hline 1 & 80 & 12 & 16 & 36.3 & 34.93 & 3.77 \\
\hline 2 & 60 & 9 & 16 & 40.8 & 40.27 & 1.30 \\
\hline 3 & 60 & 15 & 16 & 42.8 & 41.59 & 2.83 \\
\hline 4 & 60 & 12 & 20 & 47.0 & 45.89 & 2.36 \\
\hline 5 & 60 & 15 & 24 & 49.8 & 48.11 & 3.40 \\
\hline 6 & 40 & 9 & 20 & 53.4 & 53.07 & 0.61 \\
\hline 7 & 80 & 12 & 24 & 40.1 & 39.02 & 2.70 \\
\hline 8 & 40 & 15 & 20 & 56.2 & 56.15 & 0.10 \\
\hline 9 & 80 & 9 & 20 & 37.6 & 35.39 & 5.87 \\
\hline 10 & 40 & 12 & 24 & 61.4 & 60.50 & 1.47 \\
\hline 11 & 60 & 12 & 20 & 47.0 & 45.89 & 2.36 \\
\hline 12 & 60 & 12 & 20 & 47.0 & 45.89 & 2.36 \\
\hline 13 & 80 & 15 & 20 & 37.4 & 35.35 & 5.50 \\
\hline 14 & 60 & 9 & 24 & 47.4 & 46.41 & 2.10 \\
\hline 15 & 40 & 12 & 16 & 53.2 & 51.93 & 2.39 \\
\hline
\end{tabular}

Table 4. Abrasion loss of hand tufted carpets

From the experimental results reported in Table 4, 
the following response surface equation 1 was obtained. This equation contains 9 terms arising from 3, 3 and 3 linear, interaction and quadratic terms respectively.

The coefficient of determination $\left(\mathrm{R}^{2}\right)$ of the aforesaid model is 0.997 . This implies that the model can explain around $99 \%$ variability present in the experimental data. All carpet samples are showing less than $6 \%$ prediction error. Therefore, it can be inferred that the derived model is perfect in terms of prediction accuracy.

$y=9.250-0.285 x_{1}+5.408 x_{2}+1.775 x_{3}-0.013 x_{1} x_{2}-0.014 x_{1} x_{3}$ $+0.008 x_{2} x_{3}+0.002 x_{1}^{2}-0.189 x_{2}^{2}-0.006 x_{3}^{2}$

The ANOVA results of the regression model are shown in Table 5. The significance of the entire model and each of the coefficients was checked by using F-test and its associated $\mathrm{p}$-value. If the p-value is less than 0.05 then the model is statistically significant at $95 \%$ level. The model $\mathrm{F}$ value of 182.87 indicates that it is significant and there is less than $0.01 \%$ chance that F-value this large could occur due to chance.

\begin{tabular}{|c|c|c|c|c|c|}
\hline $\begin{array}{l}\mathscr{S} \\
\stackrel{\Xi}{8} \\
\text { है }\end{array}$ & 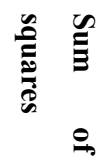 & 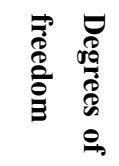 & 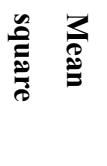 & 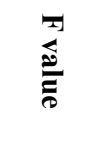 & 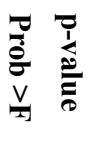 \\
\hline Model & 771.90 & 9.00 & 85.77 & $\begin{array}{l}182.8 \\
7\end{array}$ & $\begin{array}{l}<0.00 \\
01\end{array}$ \\
\hline $\begin{array}{l}\mathrm{x}_{1}-\text { Viscos } \\
\text { e Blend }\end{array}$ & 662.48 & 1.00 & 662.48 & $\begin{array}{l}1412 . \\
54\end{array}$ & $\begin{array}{l}<0.00 \\
01\end{array}$ \\
\hline $\begin{array}{l}\mathrm{x}_{2} \text {-Pile } \\
\text { height }\end{array}$ & 6.13 & 1.00 & 6.13 & 13.06 & $\begin{array}{l}0.015 \\
3\end{array}$ \\
\hline $\begin{array}{l}\mathrm{x}_{3} \text {-Pile } \\
\text { density }\end{array}$ & 81.92 & 1.00 & 81.92 & $\begin{array}{l}174.6 \\
7 \\
\end{array}$ & $\begin{array}{l}<0.00 \\
01\end{array}$ \\
\hline $\mathrm{x}_{1} \mathrm{x}_{2}$ & 2.25 & 1.00 & 2.25 & 4.80 & $\begin{array}{l}0.080 \\
1\end{array}$ \\
\hline $\mathrm{x}_{1} \mathrm{x}_{3}$ & 4.84 & 1.00 & 4.84 & 10.32 & $\begin{array}{l}0.023 \\
7 \\
\end{array}$ \\
\hline$x_{2} x_{3}$ & 0.04 & 1.00 & 0.04 & 0.09 & $\begin{array}{l}0.782 \\
0\end{array}$ \\
\hline $\mathrm{x}_{1}{ }^{2}$ & 2.67 & 1.00 & 2.67 & 5.69 & $\begin{array}{l}0.062 \\
8\end{array}$ \\
\hline $\mathrm{x}_{2}{ }^{2}$ & 10.00 & 1.00 & 10.67 & 22.75 & $\begin{array}{l}0.005 \\
0 \\
\end{array}$ \\
\hline $\mathrm{x}_{3}{ }^{2}$ & 0.04 & 1.00 & 0.04 & 0.08 & $\begin{array}{l}0.790 \\
3\end{array}$ \\
\hline
\end{tabular}

\begin{tabular}{|l|l|l|l|l|l|}
\hline Residual & 67.00 & 5.00 & 0.47 & & \\
\hline Cor Total & 774.25 & 14.00 & & & \\
\hline
\end{tabular}

Table 5. Analysis of variance for abrasion loss

In this case, all terms are statistically significant except $\mathrm{x}_{2} \mathrm{x}_{3}$ (interaction term of pile height and pile density) and $\mathrm{x}_{3}{ }^{2}$ (quadratic term of pile density). If the $\mathrm{p}$-value is greater than 0.1 then that model term is not significant.

\subsection{Analysis of contour graphs}

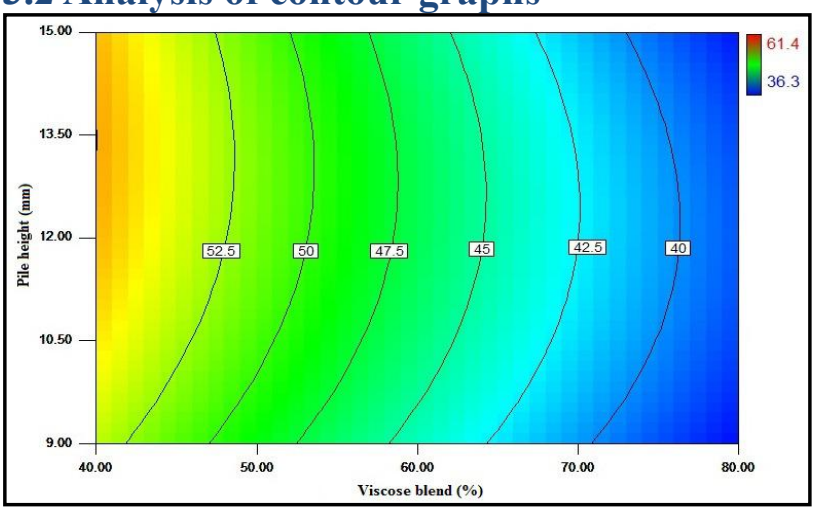

Figure 4; Effect of pile height and viscose blend on abrasion.

Figure 4 depicts the effect of pile height and viscose blend on abrasion loss of hand tufted carpets. The carpet pile abrasion loss is lowest at the maximum blend $\%$ of viscose and minimum blend $\%$ of wool. It may be due to when the content of wool fibres is lowest in the blend then extraction of short fibres from pile yarns is minimum. The abrasion loss of carpets increases with the increase in pile height. It has been reported that small fibres are constantly removed from the exterior of the carpet pile yarns during abrasion ${ }^{[12]}$. When pile height is increased, then the possibility of fibre loss increases causing higher abrasion loss ${ }^{[14]}$.

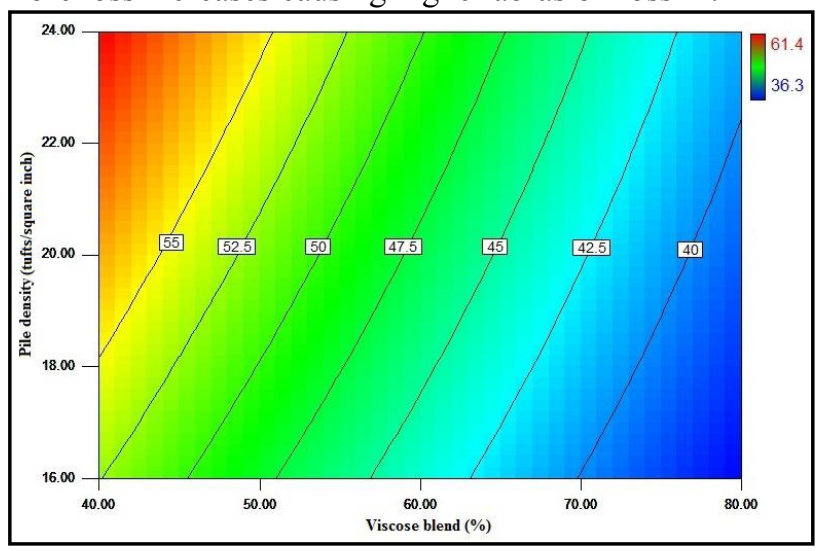

Figure 5; Effect of pile density and viscose blend on abrasion. 
Figure 5 shows the effect of pile density and viscose blend on the abrasion loss of hand tufted carpets. It is noted that abrasion loss is minimum when viscose blend is at maximum level and pile density is at minimum level. Abrasion loss increases with the increase in pile density due to the drastic increase in the number of piles per unit area ${ }^{[14]}$.

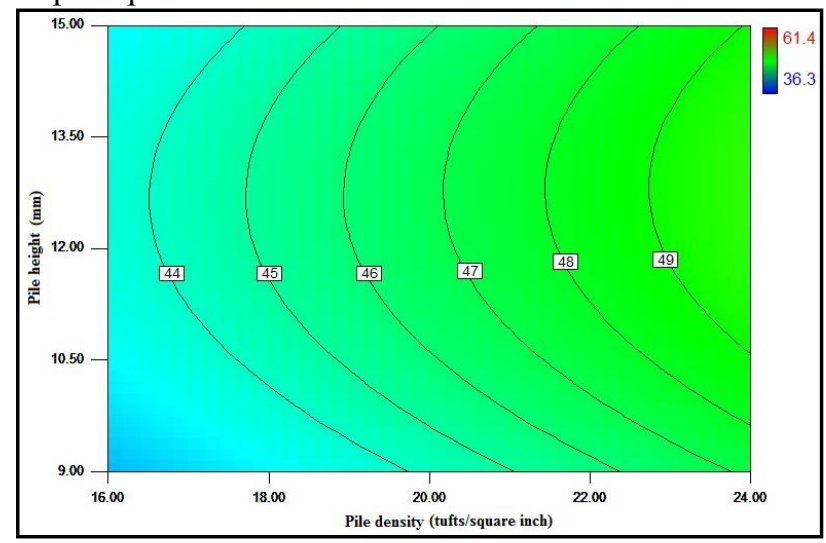

Figure 6; Effect of pile height and pile density on abrasion.

Figure 6 depicts the influence of two carpet construction parameters (pile density and pile height) on abrasion loss. It is observed that abrasion loss is lowest at the minimum levels of pile density and pile height. With the increase in pile density, abrasion loss increases due to the increase in the number of piles per unit area.

\section{Conclusions}

The influence of viscose blend, pile height and pile density on the abrasion loss of hand tufted has been investigated. All terms except $\mathrm{x}_{2} \mathrm{x}_{3}$ (interaction term of pile height and pile density) and $\mathrm{x}_{3}{ }^{2}$ (quadratic term of pile density) are found to be statistically significant. The abrasion loss decreases with the increase in blend \% of viscose. The abrasion loss of wool-viscose hand tufted carpets increases significantly with the increase in pile height and pile density. Overall; higher $\%$ of viscose in the blend, lower pile height and lower pile density yield the minimum abrasion loss for the hand tufted carpets.

\section{References}

1. http://www.indiancarpets.com/pdf/India-A-GlobalLeader-in-Handmade-Carpets.pdf accessed on 06.05.2018

2. IS: 11205. 1984. Indian standards specifications. New Delhi: Bureau of Indian Standards.

3. Crawshaw G H, "Carpet Manufacture", pp. 158-163, Wronz Developments, New Zealand,
2002.

4. Liu F, Maher A P, Lappage J and Wood E J, The measurement of the tuft-withdrawal force in machine-made and hand-knotted carpet. J. Text. Inst., 2002; 93(3): 276-282.

5. Topalbekiroglu M, Kireçci A and Dülger C L, Design of a pile-yarn manipulating mechanism. Proceedings of the Institution of Mechanical Engineers, Part B: J. Engg. Man.; 2005; 219: 539.

6. Goswami K K, "Advances in Carpet Manufacture", pp. 201-202, Cambridge: Woodhead Publishing Limited, 2009.

7. Gupta S K, Goswami K K and Majumdar A, Durability of handmade wool carpets: A review. J Nat Fibers, 2015; 12(5): 399-418.

8. Gupta N P, Shakyawar D B and Sinha R D, Influence of fibre diameter and medullation on woollen spun yarns and their products. Ind. J. Fibre. Tex. Res., 1998; 23: 32-37.

9. Shakyawar D B, Gupta N P, Patni P C and Arora R $\mathrm{K}$, Computer-aided statistical module for hand-knotted carpets. Ind. J. Fibre. Tex. Res., 2008; 33(4): 405-410.

10. Arora R K, Patni P C, Dhillon R S and Bapna D L, Influence of tuft constitution on performance properties of hand-woven carpets. Ind. J. Fibre. Tex. Res., 1999; 24: 111-114.

11. Schiefer H F and Cleveland R S, U. S. Department of commerce, Bureau of standards, Research paper RP 640, Part of Bureau of Stand. J. Res., 1934; 12: 155.

12. Önder E and Berkalp Ö B, Effects of different structural parameters on carpet physical properties. Text. Res. J., 2001; 71: 549-555.

13. Noonan K K, The wear to backing of wool and other carpets in a turning trial. J. Text. Inst., 1973; 64(9): 528-533.

14. Gupta S K, Goswami K K and Majumdar A, Modeling of Abrasion Resistance of Persian Handmade Wool Carpets using Response Surface Methodology. Fibers \&amp; Polymers, 2016; 17(4): 637-643.

15. Box G E P and Behnken D W, Some New Three Level Designs for the Study of Quantitative Variables.Technometrics; 1960; 2: 455-475. 